\title{
Wer also erzählt Nietzsches Zarathustra?
}

\author{
Claus Zittel
}

Angenommen: 29. Juli 2021 / Online publiziert: 30. August 2021

(C) Der/die Autor(en) 2021

Zusammenfassung Dass Also sprach Zarathustra einen Erzähler hat, wird meist übersehen. Der Beitrag arbeitet die unterschiedlichen Rollen und Funktionen des Erzählers in Nietzsches Hauptwerk heraus, diskutiert die damit verbundene Gattungsproblematik und fragt nach den Formen und Folgen eines Erzählens nach dem Tode Gottes. Es werden die unterschiedlichen Störungen in der Erzählordnung vorgeführt und diese im Licht einer chaotisch und kontingent gewordenen Moderne interpretiert.

\section{Who thus narrates Nietzsche's Zarathustra?}

Abstract The article elaborates the significance of the different roles and functions of the narrator in Nietzsche's main work, which are usually neglected by Nietzsche research, discusses the problem of genre and asks about the forms and consequences of narration after the death of God. The various disturbances in the narrative order are presented and interpreted in the light of a modernity that has become chaotic and contingent.

\footnotetext{
Die folgenden Überlegungen schließen an einen früheren Aufsatz an: »Sprüche, Brüche, Widersprüche. Irritationen und Deutungsprobleme beobachtet am Erzählverhalten und an der Erzählperspektive in Nietzsches >Also sprach Zarathustra««, Nietzscheforschung (2002), 289-300. Damals habe ich Beispiele für die Staffelung von Erzählebenen im Zarathustra gegeben sowie die Funktion der Rollenprosa und der zahlreichen Fiktionsbrüche beschrieben, diesmal versuche ich den schwer greifbaren Erzähler einzufangen. Für hilfreiche Hinweise und Kritik danke ich Giulia Baldelli, Felix Christen, Wolfram Groddeck, Martin Kölbl, Enrico Müller, Imelda Rohrbacher und Peter Villwock.
}

Claus Zittel $(\bowtie)$

Stuttgart Research Centre for Text Studies, Azenbergstr. 12, 70174 Stuttgart, Deutschland

E-Mail: claus.zittel@ts.uni-stuttgart.de; claus.zittel@unive.it

Dipartimento di studi linguistici e culturali comparati, Università Ca’ Foscari Venezia, Dorsoduro 1405, 30123 Venedig, Italien 


\section{Bilderreigen und Erzähllabyrinth}

»Wer ist Nietzsches Zarathustra? « ${ }^{1}$ fragte einst in einem nachmals berühmt gewordenen Aufsatz Martin Heidegger. »Der Lehrer der ewigen Wiederkunft« und »der Fürsprecher des Lebens, der Fürsprecher des Leidens, der Fürsprecher des Kreises [...] der Fürsprecher dessen [...], daß alles Seiende Wille zur Macht ist, der als schaffender, sich stoßender Wille leidet und so sich selber in der ewigen Wiederkehr des Gleichen will $\ll^{2}$, lautete bekanntlich Heideggers bedeutungsschwere Antwort. »Was ist Nietzsches Zarathustra? «3 verspricht nun ein jüngerer Buchtitel zu verraten, dessen Verfasser (wie viele vor ihm) uns darüber aufklärt, dass Zarathustra ein Prophet und Also sprach Zarathustra ein die Bibel parodierendes Drama sei. Wie bei Heidegger wird die literarische Form lediglich als Vehikel für die Vermittlung weltanschaulicher Lehren aufgefasst. ${ }^{4}$ Aber auch jene Interpreten, die sich für die ästhetische Gestalt des Zarathustra interessieren, fragen kaum je nach seinem Erzähler. Es gibt Arbeiten zur Sprachform des Zarathustra, ${ }^{5}$ zu seinen Motiv-Ketten und rhythmisch-metaphorischen Bedeutungsfeldern, ${ }^{6}$ den Kommunikationsformen ${ }^{7}$ und rhetorischen Strukturen ${ }^{8}$ im interkulturellen Vergleich ${ }^{9}$ sowie den intertextuellen Bezügen, daneben auch Stilanalysen ${ }^{10}$ und Gattungsdiskussionen. ${ }^{11}$ Für die meisten Interpreten jedoch scheint der Erzähler des Zarathustra hinter dem Redner

\footnotetext{
1 Martin Heidegger, »Wer ist Nietzsches Zarathustra?«, in: Ders., Vorträge und Aufsätze, Pfullingen 1954. Vgl. auch Günter Wohlfahrt, »Wer ist Nietzsches Zarathustra?«, Nietzsche-Studien 26 (1997), 319-330. Wohlfahrt variiert und bestätigt Heideggers Deutung mit Hilfe der hermeneutischen Hypothese, dass Heraklit Nietzsches Zarathustra präfiguriert.

2 Heidegger (Anm. 1), 99.

3 Heinrich Meier, Was ist Nietzsches Zarathustra? Eine philosophische Auseinandersetzung, München 2017. Vgl. dazu kritisch: Katharina Grätz, »Neuerscheinungen zu Also sprach Zarathustra«, NietzscheStudien 2017, 333-343. Felix Christen, »Einleitung«, in: Also sprach Zarathustra. Ein Buch für Alle und Keinen, hrsg. und eingeleitet von Felix Christen, Stuttgart 2014, IX-XLVI.

4 Auch die Beiträge im Sammelband von Mathias Mayer (Hrsg.), Also wie sprach Zarathustra? Westöstliche Spiegelungen im kulturgeschichtlichen Vergleich, Würzburg 2006, verstehen die Wie-Frage nicht erzähltechnisch. Der wichtigste, sich den Formproblemen des Zarathustra widmende neuere Band ist: Gabriella Pelloni, Isolde Schiffermüller (Hrsg.), Pathos, Parodie, Kryptomnesie. Das Gedächtnis der Literatur in Nietzsches »Also sprach Zarathustra", Heidelberg 2015.

5 Siegfried Vitens, Die Sprachkunst Friedrich Nietzsches in »Also sprach Zarathustra«, Bremen 1951.

${ }^{6}$ Ferruccio Masini, »Rhythmisch-metaphorische Bedeutungsfelder in Also sprach Zarathustra«, Nietzsche-Studien 2 (1973), 276-307.

7 Anke Bennholdt-Thomsen, Nietzsches »Also sprach Zarathustra« als literarisches Phänomen, Frankfurt a. M. 1974.

8 Peter Gasser, Rhetorische Philosophie. Leseversuche zum metaphorischen Diskurs in Nietzsches »Also sprach Zarathustra«, Bern u.a. 1992.

9 Mayer (Hrsg.) (Anm. 4).

10 Karl Groos, »Der paradoxe Stil in Nietzsches Zarathustra«, Zeitschrift für angewandte Psychologie und physiologische Sammelforschung, Bd. 7 (1913), 467-529. Gary Shapiro, Nietzschean Narratives, Indiana 1989; Alexander Nehamas, Nietzsche: Life as Literature, Cambridge 1985.

11 Rüdiger Braun, Quellmund der Geschichte. Nietzsches poetische Rede in »Also sprach Zarathustra«, Frankfurt a. M. 1998.
} 
Zarathustra verborgen zu bleiben oder gar nicht zu existieren. Unter den in Myriaden auftretenden Zarathustra-Deutungen finden sich jedenfalls bislang nur eine unbeachtet gebliebene größere Studie ${ }^{12}$ und drei Aufsätze, die unabhängig voneinander die Erzählstruktur des Zarathustra als Hauptgegenstand der Analyse gewählt haben. ${ }^{13}$ Sie sind dabei zu sehr unterschiedlichen Resultaten gelangt, weshalb eine Diskussion des bisher Beobachteten und weitere Untersuchungen nötig sind.

Wer den in Also sprach Zarathustra indes allgegenwärtigen Erzähler bemerkt, kann nicht gleich davon ausgehen, eine erzählende Dichtung vor sich zu haben, da neben den erzählerischen Partien auch dramatische, ${ }^{14}$ rhetorische und lyrische Formen stehen. ${ }^{15}$ Zwar ist der Rahmen des heterogenen Sprachkunstwerks Zarathustra eindeutig erzählerisch, dieser Rahmen aber wird immer wieder aus den Angeln gehoben, gesprengt oder verlassen.

Gelegentlich wurde der Zarathustra allgemein als Roman ${ }^{16}$ sowie spezifischer als romantisch-progressiver Roman ${ }^{17}$ oder gar Bildungsroman ${ }^{18}$ bezeichnet, obgleich er die für den Bildungsroman grundlegenden Ordnungsvorstellungen der bürgerlichen

\footnotetext{
12 John Carson Pettey, Nietzsche's Philosophical and Narrative Styles, Bern 1992.

${ }^{13}$ Elrud Kunne-Ibsch, »Textstruktur und Rezeptionsprozess am Beispiel von Nietzsches `Zarathustra «, in: Comparative poetics, Poetique comparative, Vergleichende Poetik, hrsg. D. W. Fokkema et al., Amsterdam 1976, 215-242; Katharina Grätz, »Zarathustra als fiktive Figur«, in: Dies., Sebastian Kaufmann (Hrsg.), Nietzsche zwischen Literatur und Philosophie. Von der »Fröhlichen Wissenschaft«zu»Also sprach Zarathustra«, Heidelberg 2016, 357-376, insbesondere: 366-375; Zittel, »Sprüche, Brüche, Widersprüche«, 289-300. Einzelbeobachtungen finden sich zudem verstreut, z.B. bei Werner Stegmaier, »Also sprach Zarathustra«, in: Ders., Hauptwerke der Philosophie. Von Kant bis Nietzsche, Stuttgart 1997, 402-442, insbes. 412f.; Douglas Burnham, Martin Jesinghausen, Nietzsche's Thus Spoke Zarathustra. An Edinburgh Philosophical Guide, Edinburgh 2010, 64; Paul Loeb, The death of Nietzsche's Zarathustra, Cambridge 2010, 94.

${ }^{14}$ Hans-Georg Gadamer, »Das Drama Zarathustras«, Nietzsche-Studien 16 (1986), 1-15; Winfried Happ, Nietzsches »Zarathustra« als moderne Tragödie, Frankfurt a. M. 1984; Sylvain de Bleeckere, »Also sprach Zarathustra. Die Neugestaltung der >Geburt der Tragödie««, Nietzsche-Studien 8 (1979), 270-290.
}

15 Zur Gattungsfrage vgl. Verf., Das ästhetische Kalkül von Friedrich Nietzsches »Also sprach Zarathustra«, Würzburg 2011, 66-70. Elrud Kunne-Ibsch (Anm. 13); Pettey (Anm. 12), 133-140.

16 Julius Zeitler, Nietzsches Ästhetik, Leipzig 1900, 237-264; Kathleen M. Higgins, Nietzsche's Zarathustra, Philadelphia 1987; Christoph König, »IIch bin dein Labyrinth ...<. Zur poetischen Klugheit in Nietzsches Dionysos-Dithyramben«, in: Christian Benne, Claus Zittel (Hrsg.), Nietzsche und die Lyrik. Ein Kompendium, Stuttgart 2017, 331-349.

17 Christoph König vermeidet zwar klischeebehaftete Kohärenzunterstellungen, wenn er den Zarathustra als »Roman im frühromantischen Sinne einer progressiven Mischung der Gattungen« bestimmt, gleichwohl bleibt bei ihm unter vielem anderen unklar, wie frühromantische Reflexions- und Allegoriebegriffe mit Nietzsches Sprachkritik zu vereinbaren sind und worin die Progression der Gattungsmischung bestehen soll. Welcher romantische Roman könnte als Vorbild genannt werden? König (Anm. 16), 331.

18 Vgl. Higgins (Anm.16), 100 u. 104f. Vgl. David E. Cartwright, »The Last Temptation of Zarathustra«, Journal of the History of Philosophy (1993) 1, 49-69, hier: 50. John Clayton, »Zarathustra und die Stadien auf dem Lebensweg«, in: Romantik. Literatur und Philosophie, hrsg. Volker Bohn, Frankfurt a. M. 1987, 257-278; Daniel Conway, »Nietzsche contra Nietzsche: The Deconstruction of Zarathustra«, in: Clayton Koelb (Hrsg.), Nietzsche as postmodernist, New York 1990, 91-110, hier: 94; Robert GoodingWilliams, »The drama of Nietzsche's Zarathustra: Intention, Repetition, Prelude«, International Studies in Philosophy XX/2 (1988), 105-116, hier: $110 \mathrm{ff}$. 
Welt konsequent negiert. ${ }^{19}$ Verglichen hat man ihn zudem mit dem romantischen Kunstmärchen ${ }^{20}$, aber ihn auch schlicht, weil nichts wirklich passt, als »unzeitgemässen Roman $\ll^{21}$ bestimmt.

$\mathrm{Zu}$ bedenken wäre allerdings Nietzsches eigene Definition des Romans als »unendlich gesteigerte äsopische Fabel«, welche die Poesie in sich aufnehme, unter die Herrschaft der Dialektik zwinge und so das Erbe des platonischen Dialogs antrete. ${ }^{22}$ Sie ist bemerkenswert, weil Nietzsche mit ihr eine Alternative zu den üblichen romantheoretischen Erklärungen, dass sich der Roman aus dem homerischen Epos oder aus Sagen- und Novellensammlungen (Erwin Rohde) ${ }^{23}$ entwickelt habe, formuliert und die Paradoxien vor Augen stellt, in welche er durch sein Reflexivwerden steuert. Im Roman triumphiere die Philosophie über die Dichtkunst und behindere seither den Strom epischen Erzählens. ${ }^{24}$

Eine solche Dominanz des Philosophischen ist offensichtlich auch in Also sprach Zarathustra gegeben. Durch den Verzicht auf eine psychologische Figurenzeichnung und der damit einhergehenden Verweigerung kausaler Handlungsmotivationen erscheint der Zarathustra primär als lockere Abfolge von Ereignissen ohne ursächlichen Zusammenhang. Ein Geschehen wird erzählt, aber keine Geschichte. Damit scheiden etliche Roman-Varianten als Gattungsmuster aus. Doch wenn keine Ge-

\footnotetext{
19 Also sprach Zarathustra als Bildungsroman zu lesen, geht schon deswegen fehl, da es in ihm keine individuellen, mit einem Innenleben ausgestattete Charaktere gibt, die sich durch ihre Erfahrungen mit der Welt entwickeln.

20 Vgl. Rüdiger Ziemann, »Das liebe ewige Leben. Zur Brentanolektüre des jungen Nietzsche«, Nietzscheforschung 1 (1994), 335-350, hier: 342.

21 Pettey (Anm. 12), 140.

22 Vgl.: »Der platonische Dialog war gleichsam der Kahn, auf dem sich die schiffbrüchige ältere Poesie sammt allen ihren Kindern rettete: auf einen engen Raum zusammengedrängt und dem einen Steuermann Sokrates ängstlich unterthänig fuhren sie jetzt in eine neue Welt hinein, die an dem phantastischen Bilde dieses Aufzugs sich nie satt sehen konnte. Wirklich hat für die ganze Nachwelt Plato das Vorbild einer neuen Kunstform gegeben, das Vorbild des R o m a n's: der als die unendlich gesteigerte äsopische Fabel zu bezeichnen ist, in der die Poesie in einer ähnlichen Rangordnung zur dialektischen Philosophie lebt, wie viele Jahrhunderte hindurch dieselbe Philosophie zur Theologie: nämlich als ancilla. Dies war die neue Stellung der Poesie, in die sie Plato unter dem Drucke des dämonischen Sokrates drängte.« Friedrich Nietzsche, Sokrates und die griechische Tragödie, in: Ders., Kritische Studienausgabe in 15 Bänden (KSA), hrsg. Giorgio Colli, Mazzino Montinari, München, New York 1980, Bd. 1, 632. Nietzsches Schriften werden bei mehrfacher Erwähnung nach den folgenden Siglen plus Aphorismen- oder Fragment-Nummer, Band und Seitenzahl der KSA oder KGW (Friedrich Nietzsche: Werke. Kritische Gesamtausgabe, begründet von Giorgio Colli, Mazzino Montinari, Berlin $1969 \mathrm{ff}$.) zitiert: FW = Die fröhliche Wissenschaft; GM = Zur Genealogie der Moral; GT = Die Geburt der Tragödie aus dem Geiste der Musik; MA = Menschliches, Allzumenschliches $\mathrm{I}$ und II; NF = Nachgelassene Fragmente; $\mathrm{M}=$ Morgenröthe; $\mathrm{VM}=$ Vermischte Meinungen und Sprüche; $\mathrm{Za}=$ Also sprach Zarathustra.

23 Erwin Rohde, Der griechische Roman und seine Vorläufer, Leipzig 1876.

24 Der realistische Roman wird auch später für Nietzsche nie eine Option sein, um der entzauberten Welt prägnanten Ausdruck zu verleihen. Das trennt Nietzsche entschieden von der Romantheorie Lukács', bringt ihn aber in die Nähe von Adornos Bestimmung des antirealistischen Romans der Moderne. Vgl. Georg Lukács, Theorie des Romans. Ein geschichtsphilosophischer Versuch über die Formen der großen Epik. Zweite um ein Vorwort vermehrte Auflage, Neuwied am Rhein, Berlin-Spandau 1963; Theodor W. Adorno, »Über epische Naivität«, in: Ders., Noten zur Literatur, Frankfurt a. M. 1974, 34-40; ders., »Der Standort des Erzählers im zeitgenössischen Roman«, ebd., 41-47.
} 
schichte erzählt wird, haben wir es dann überhaupt noch mit irgendeiner Art von »philosophischer Grosserzählung « ${ }^{25} \mathrm{zu}$ tun?

Vorsicht ist geboten, weshalb zunächst hier nicht mehr versucht werden soll, als einen ersten Überblick über die diversen Erzählstrategien zu gewinnen. Ob diese dann den Zarathustra als Roman konstituieren, welcher im epischen Rahmen lyrische, dramatische und rhetorische Formen zu einer harmonischen oder progressiven Synthese vereint, ist jedoch zweifelhaft. Die mit den jeweiligen Gattungsbegriffen einhergehenden Lesererwartungen z.B. an den Handlungsverlauf und die Dramaturgie werden aufgerufen, aber nie befriedigend erfüllt. So stellt sich die Leseerfahrung ein, dass die in diesem Text unterschiedlich gewichteten, aber formal gleichberechtigten Einzelelemente verschiedene transitorische Einheitsfiktionen (Lehrdichtung, Versepos, Drama, Roman, Legende, Gesamtkunstwerk, Bibelparodie, Satire) erzeugen, die sich wechselseitig wieder vernichten.

Die folgenden Überlegungen zielen daher nicht auf eine Gattungsbestimmung ab, sondern lediglich auf eine tentative Funktionsanalyse der Erzählverfahren. Die so gewonnenen Befunde erhellen nur einen Aspekt und müssen für eine Gesamtdeutung erst noch in Beziehung zu den anderen textorganisierenden Verfahren (wie z.B. den inter- und intratextuellen Verweisungen, den Metaphernketten, Wiederholungsstrukturen, Leitmotive und Handlungsmuster, Wort-, Assonanzen- und Maskenspiele, Figurenkonstellationen und Charakterwandel, Redesituationen, Fremdund Selbstparodien, Orts- und Perspektivenwechsel) gesetzt werden. Doch um das Zusammenspiel der ästhetischen Verfahren und dessen Sinn, das ästhetische Kalkül ${ }^{26}$ des experimentellen »Form-Hybrids $\ll^{27}$ in den Blick zu bekommen, wird man inter alia auch die Erzählstruktur beachten müssen. Da zudem die Protagonisten keine fixen Identitäten haben, sondern unterschiedliche Rollen übernehmen können und im vierten Teil einzelne Figuren Zarathustras Reden parodieren, kommt es durch die ständigen Standpunktwechsel zu einer polyperspektivischen Auffächerung der Figurensichten, deren Panorama nur durch die ganze Erzählung sichtbar wird. ${ }^{28}$ Wenn wir für eine Weile diese Perspektive einnehmen, so erscheint uns der Zarathustra als ein Bilderreigen in einem Erzähllabyrinth.

\section{II.}

\section{Die Kunst des Erzählens}

Unter diesem Eindruck haben wir uns zu vergegenwärtigen, dass Nietzsche durchaus einen Sinn für erzähltechnische Fragen und damit verbunden ein feines Gespür für die literarische Qualität von Erzählwerken hatte. Petronius' Satyricon, Cervantes' Don Quichote, Sternes Tristram Shandy, Diderots Jacques le Fataliste et son maître, Stendhals Armance und Die Kartause von Parma, Stifters Nachsommer, Kel-

\footnotetext{
25 Enrico Müller, Nietzsche-Lexikon, Paderborn 2020, 67.

26 Zittel (Anm. 15).

27 Müller (Anm. 25), 71.

28 Vgl. Zittel, »Sprüche, Brüche, Widersprüche«.
} 
lers Grüner Heinrich, Dostojewskis Die Dämonen, Hölderlins Hyperion - die Liste herausragender Romane, die Nietzsche für ihre komplexe Erzählkunst schätzte, ist verblüffend. Spät noch bekennt er, dass es Goethes Löwennovelle gewesen sei, die seinen ästhetischen Sinn für immer geprägt habe. ${ }^{29}$ Ungeachtet des bei ihm ubiquitären tragischen Pathos kürt er zum »freiesten Schriftsteller « gerade keinen von der geschlossenen Form seiner Dichtung abhängenden Tragiker, sondern einen Romancier: Laurence Sterne. An Sternes Kunst rühmt Nietzsche gerade, dass in ihr »die bestimmte Form fortwährend gebrochen, verschoben, in das Unbestimmte zurückübersetzt wird, sodass sie das Eine und zugleich das Andere bedeutet.« Sterne sei daher »der grosse Meister der Zweideutigkeit«, er verstehe es »Tiefsinn und die Posse zu verknäueln « und bringe bei seinen Lesern durch seine Ironie und Rollenwechsel fortwährend ein »Gefühl von Unsicherheit darüber hervor, ob man gehe, stehe oder liege: ein Gefühl, welches dem des Schwebens am verwandtesten ist. [...] Sein Buch gleicht einem Schauspiel im Schauspiel, einem Theaterpublicum vor einem andern Theaterpublicum. «(MA II 113, KSA 2, 424-426). ${ }^{30}$

Nietzsches luzide Reflexionen über die Kunst der Prosa stehen jedoch ganz im Schatten seiner vielbeachteten Tragödientheorie. Das mag - neben der Persistenz des vordergründigen Bibelparodie-Klischees - ein weiterer Grund dafür sein, weshalb man Nietzsches Ideal der freien Schriftstellerei nicht sofort mit Also sprach Zarathustra in Verbindung brachte. Doch auch aufgrund der von Nietzsche selbst in die Welt gesetzten Legende, ${ }^{31}$ dass er sein Hauptwerk in drei Inspirationsräuschen als »Zehn-Tage-Werke « heruntergeschrieben habe, ${ }^{32}$ wurden seine eigenen Überlegungen zu einer Kunst des Erzählens, die sehr genau die Wirkung jedes narrativen Details bedenken, von den Interpreten des Zarathustra nahezu nie berücksichtigt.

Dass ein rein inhaltsorientiertes Lesen die Kunst des Erzählers verkenne, hatte Nietzsche bereits in der Zeit von Menschliches, Allzumenschliches moniert. Heutzutage sei die Lage so: »jeder pflückt sich, was ihm schmeckt; wir stehen nicht in dem nothwendigen Verhältnisse zu diesen Kunstwerken«, weshalb »jetzt alles, was ein Erzähler gut macht, beim heutigen Publikum verloren geht: welches nur den Stoff der Erzählung will und interessirt fortgerissen überwältigt sein möchte: durch das Faktum, welches die Criminalakten z.B. am besten enthalten, nicht durch die Kunst des Erzählers.« (NF 19 [88] 1876, KSA 8, 352) Das kann man schon als

\footnotetext{
29 »Was Goethe angeht: so war der erste Eindruck, ein sehr früher Eindruck, vollkommen entscheidend: die Löwen-Novelle, seltsamer Weise das Erste, was ich von ihm kennen lernte, gab mir ein für alle Mal meinen Begriff, meinen Geschmack »Goethe«.« (NF 1888, 24 [10], KSA 13, 634).

$30 \mathrm{Zu}$ Nietzsche und Sterne siehe: Vivetta Vivarelli, Nietzsche und die Masken des Freien Geistes: Montaigne, Pascal und Sterne, Würzburg 1998; Claus Zittel, »Nietzsches Yori(c)k. Falsche Fährten und verlorene Leser in Nietzsches Bibliothek«, in: Hans-Peter Anschütz, Armin Thomas Müller, Mike Rottmann, Yannick Souladié (Hrsg.), Nietzsche als Leser, Berlin 2021, 383-402.

31 »Ich erzähle nunmehr die Geschichte von Zarathustra« behauptet Nietzsche in Ecce Homo (KSA 6, 335) - woraufhin er die Entstehungsgeschichte seines Hauptwerks in Form einer Legende erzählt. Eine Spur ist damit gelegt, auf der ein versierter Leser ihm auf die Schliche kommen kann.

32 Vgl. dagegen die philologischen Widerlegungen in Montinaris Kommentar zur KSA (KSA 14, 279-282) und in Marie-Luise Haases »Nachbericht« zum Zarathustra-Band: KGW IV 2, 943-978; Mazzino Montinari, »Zarathustra vor >Also sprach Zarathustra««, in: Ders., Nietzsche lesen, Berlin, New York 1971, 79-91; Peter Villwock, »Zarathustra. Anfang und Ende einer Werk-Gestalt Nietzsches «, in: Ders. (Hrsg.), Nietzsches »Also sprach Zarathustra«, Basel 2001, 1-34.
} 
einen Kommentar avant la lettre zur Zarathustra-Rezeption lesen. Allerdings lasse ein Erzähler

leicht merken, ob er erzählt, weil ihn das Factum interessirt oder weil er durch die Erzählung interessiren will. Im letzteren Falle wird er übertreiben, Superlative gebrauchen und Ähnliches thun. Er erzählt dann gewöhnlich schlechter, weil er nicht so sehr an die Sache, als an sich denkt. (MA I 343).

Nietzsches »Buch für Alle und Keinen« ist offensichtlich voll von Übertreibungen. Es ist immer das Extreme, was Zarathustra widerfährt: Er steigt aus der tiefsten Tiefe auf die höchsten Berge und taucht in die schwärzesten Fluten, er trägt das größte Schwergewicht und hört die stillste Stunde. Diese Superlativ-Parade würde einem gewöhnlichen Erzähler als Schwäche angekreidet, es bedarf daher, so können wir folgern, eines ungewöhnlich guten Erzählers, der, obgleich er sich für sich selbst interessiert, die Hyperbolik außerordentlich kunstvoll einzusetzen versteht. Eine solche Erzählkunst lenkt die Aufmerksamkeit auf die Form. Immer wieder plädiert Nietzsche für den Primat der Form vor dem Inhalt, ja erklärt die Form zum eigentlichen Inhalt, am Eindringlichsten in diesem späten Notat:

Man ist um den Preis Künstler, daß man das, was alle Nichtkünstler >Form $<$ nennen, umgekehrt als I $\mathrm{n}$ h a $1 \mathrm{t}$, als > die Sache selbst< empfindet, dagegen den Inhalt bleß als Form (als relativ gleichgültig, willkürlich, zufällig). Damit gehört man freilich ründlich in die eine v e r k e h r t e W e $1 \mathrm{t}$ : denn nunmehr wird einem der Inhalt relativ gleichgültig, willkürlich, zufällig zu etwas bloß Formalem, atse - das eigene unser Leben eingerechnet. (NF 1887/88, W II 3, 7, 198, KGW IX) $)^{33}$

Künstler setzten insbesondere in Phasen der Dekadenz auf extreme Wirkung, deren Effekte aber seien »vom Künstler für die Künstler kräftig unterstrichen, während der Laie wähnen muss, das beständige unfreiwillige Überströmen aller Füllhörner einer ursprünglichen Natur-Kunst zu sehen.«(VM 144, KSA 2, 438).

In diesem Licht betrachtet, könnten die extremen Schaueffekte und das hyperbolische Sprechen im Zarathustra auch als eine für Künstler ostentativ inszenierte Erzählkunst aufgefasst werden und Nietzsche erschiene wie Sterne als ein »writers writer .

Seinen Anspruch, mit dem Zarathustra ein herausragendes Meisterwerk der Sprache geschaffen zu haben, kann Nietzsche jedenfalls nur geltend machen, wenn auch sein Erzähler seine Kunst beherrscht. Aufschlussreich ist hierfür eine Unterscheidung, die Nietzsche in Menschliches, Allzumenschliches I vornimmt. Es seien selbst »G u t e E r z ä h 1 e r s c h 1 e c h t e Erklärer«(MA I, 196, KSA 2, 166), das Erzählen gleichwohl ein ernstes Handwerk, das geduldiges Studium, Beobachtung, genaues Hinhören und sehr viel Übung erfordere:

\footnotetext{
33 In späterer Reinschrift: »Man ist um den Preis Künstler, dass man das, was alle Nichtkünstler >Form< nennen, als I n h a $1 \mathrm{t}$, als >die Sache selbst< empfindet. Damit gehört man freilich in eine v e $\mathrm{r} k$ e h $\mathrm{r}$ t e Welt: denn nunmehr wird einem der Inhalt zu etwas bloß Formalem, - unser Leben eingerechnet. « (NF 1888/89, 18 [6], KSA 13, 533).
} 
Man mache nur hundert und mehr Entwürfe zu Novellen, keinen länger als zwei Seiten, doch von solcher Deutlichkeit, dass jedes Wort darin nothwendig ist; man schreibe täglich Anekdoten nieder, bis man es lernt, ihre prägnanteste, wirkungsvollste Form zu finden, man sei unermüdlich im Sammeln und Ausmalen menschlicher Typen und Charaktere, man erzähle vor Allem so oft es möglich ist und höre erzählen, mit scharfem Auge und Ohr für die Wirkung auf die anderen Anwesenden, man reise wie ein Landschaftsmaler und Costümzeichner, man excerpire sich aus einzelnen Wissenschaften alles Das, was künstlerische Wirkungen macht, wenn es gut dargestellt wird, man denke endlich über die Motive der menschlichen Handlungen nach, verschmähe keinen Fingerzeig der Belehrung hierüber und sei ein Sammler von dergleichen Dingen bei Tag und Nacht. In dieser mannichfachen Übung lasse man einige zehn Jahre vorübergehen: was dann aber in der Werkstätte geschaffen wird, darf auch hinaus in das Licht der Strasse. - Wie machen es aber die Meisten? Sie fangen nicht mit dem Theile, sondern mit dem Ganzen an. Sie thun vielleicht einmal einen guten Griff, erregen Aufmerksamkeit und thun von da an immer schlechtere Griffe, aus guten, natürlichen Gründen. (MA I, 163, KSA 2, 153)

Sammeln, Ausmalen und Üben sind produktionsästhetische Begriffe, die Folgen für die Art des Werkes zeitigen, die sich aus diesen Tätigkeiten ergibt. Ein »Sammler« kreiert eine andere Art von Werk (z.B. ein Netzwerk heterogener Elemente, die er zusammenträgt bzw. für einander zugehörig hält) als ein »Genie« oder ein »Produzent. « Das Pochen auf den »E r n s t d e s H a n d w e r k s« (ebd.) bildet dementsprechend ein Leitmotiv von Nietzsches Kritik an der Genie-Ästhetik (vgl. a. MA I 164, KSA 2, 153; M 540).

Nietzsche hat das Erzählen früh geübt, zu erinnern sind die frühen Autobiografien, ${ }^{34}$ die unvollendete Novelle »Capri und Helgoland « aus dem Jahr 1859, ${ }^{35}$ das »Euphorion-Fragment « von 1862, ${ }^{36}$ eine Anekdote aus dem Jahr 1871 im Stile Kleists ${ }^{37}$ und natürlich die zahlreichen Entwürfe zum Zarathustra selbst. ${ }^{38}$ Hinzu kommen seine Beschäftigung mit Diogenes Laertios und der Anekdote als literarischer Form $^{39}$ - Anekdoten streut er selbst dann gerne in seinen Schriften ein - sowie seine Auseinandersetzung mit dem antiken Roman, zu dem sein Freund Erwin Rohde die maßgebliche Monografie verfasste. ${ }^{40}$ Ein Kulminationspunkt von Nietz-

\footnotetext{
34 Nietzsche, »Aus meinem Leben« (1858) KGW I,1, 281-311; »Mein Lebenslauf« (1861), KGW I, 2 , 255-263; siehe dazu Pettey (Anm. 12), 45-72.

35 KGW, I, 2, 84-90.

36 NF 13 [12], KGW I, 2, 446-447.

37 NF 1870-71, 8 [16], KSA 7, $225 \mathrm{f}$.

38 Vgl. Nachbericht zu KGW 6, 4, Bd. 1, Also sprach Zarathustra, hrsg. Marie-Luise Haase, Mazzino Montinari, Berlin 1991

39 Vgl. dazu: Heinrich Niehues-Pröbsting, »Anekdote als philosophiegeschichtliches Medium«, Nietzsche-Studien 12 (1983), 255-286. Ders., »Der >kurze Weg〈: Nietzsches >Cynismus «, Archiv für Begriffsgeschichte 24, 1 (1980), 103-122.
}

40 Rohde (Anm. 23). 
sches Auseinandersetzung mit den Prosaformen ist seine Bestimmung einer idealen Erzählung:

Das gute Kunstwerk der E r z ä h 1 u n g wird das Hauptmotiv so entfalten wie die Pflanze wächst, immer deutlicher sich vorbildend, bis endlich als neu und doch geahnt die Blüthe sich erschließt. Die Kunst des Novellisten ist namentlich die, das Thema präludiren zu lassen, es symbolisch mehrermal vorwegzunehmen, die Stimmung vorzubereiten, in welcher man den Ausbruch des Gewitters anticipirt, benachbarte Töne der Hauptmelodie erklingen zu machen und so auf jede Weise die erfindende Fähigkeit des Lesers zu erregen, als ob er ein Räthsel rathen sollte; dieses aber dann so zu lösen, daß des den

Leser doch noch überrascht. - [...]. - Vielleicht ist auch eine Philosophie so darzustellen, daß man die eigentliche Behauptung erst zuletzt stellt und zwar mit ungeheurem Nachdruck. (NF 1876, 23 [91], KSA 8, 435)

Nietzsches Muster ist wohlgemerkt die Novelle, die im Bereich der Epik - in etwa wie im Lyrischen das Sonett - die strengsten narrativen Vorgaben macht. Der wesentlich freiere Roman folgt diesen schon nicht mehr, und oft auch nicht einmal dem Modell des Rätsel-Ratens. Schaut man sich die Entwürfe zum Zarathustra an, fällt im Kontrast dazu auf, dass diese, wie dann auch das Werk selbst, nicht auf die Realisierung einer solcherart idealen Erzählung abzielen. Zwar hat Nietzsche den Zarathustra mit einer Symphonie verglichen, ${ }^{41}$ die Hauptmotive aber werden in ihm weder organisch entfaltet noch münden sie in ein überraschendes Finale. Da dieses Ideal für aufmerksame Leser auf ostentative Weise nicht erfüllt wird, werden wir nun dringlicher zu den Fragen zurückgeführt: Wer also erzählt Nietzsches »Zarathustra $\ll$ ? Was wird von wem erzählt? Und wie wird erzählt? Die Antworten sind gar nicht einfach zu geben.

\section{III.}

\section{Geschriebene Rede, erzählte Schrift}

Bereits der Titel: »Also sprach Zarathustra« bereitet Kopfzerbrechen, da er suggeriert, dass wir in der Folge den mündlichen Äußerungen Zarathustras lauschen. Das Präteritum und der Untertitel (»ein Buch für alle und keinen«) scheinen andererseits anzuzeigen, dass wir diese Reden nachträglich in Buchform vorgelegt bekommen, sie also, seien wir die Adressaten oder nicht, lesen werden und eine vermittelnde Instanz im Spiel ist. Von den beiden seitens der Forschung notorischen Antworten auf

\footnotetext{
41 NF 11 [197], KSA 9, 519f. Angesichts solcher Selbstcharakteristika fragt sich, ob das Verhältnis der drei oder vier Bücher zueinander überhaupt als »Sinfonie « oder ein »Drama« vorgestellt werden kann, wenn die Teile bis zum Schluss selbstständig geschrieben und konzipiert sind? Selbst in der zweiten, die ersten drei Teile zusammenfassenden Auflage des Zarathustra sind alle drei Bücher je neu paginiert!. Dann gibt es einen »Vierten und letzten Theil«, an dessen Ende zwar »Ende« steht, aber zu dem weitere Fortsetzungspläne gemacht werden. Der 4. Teil wird zudem wieder zurückgezogen. Die Gesamtstruktur ist somit fluktuierend, und nicht, wie man zunächst denkt, fix gebaut. Zur Diskussion der Werkstruktur siehe Zittel (Anm. 15), 130, Anm. 274, sowie $63 \mathrm{ff}$.
} 
die Frage nach diesen Instanzen können wir die erste, dass der Erzähler der Autor Nietzsche sei, als Unsinn beiseitelassen. Die zweite übliche Antwort, dass die Figur Zarathustra es selbst ist, die erzählt, da immer wieder so sehr »Erzählerrede und Figurenrede zusammenfliessen $\ll^{42}$, dass Letztere dominiere, wird jedoch durch den Untertitel konterkariert. Zudem heißt es nicht: »Zarathustra sprach also:«, sondern es wird die gewohnte Reihenfolge umgekehrt, das Prädikat kommt erst an zweiter und das Subjekt an dritter Stelle. Somit könnte die Emphase auf dem vorangestellten Adverb »Also«, dem >Wie< des Sprechens liegen - aber warum >also< und nicht: $>$ so $<$ ? Das altertümelnde und biblisch formelhafte »also« verweist auf die Schrifttradition und hat von vornherein einen ironischen Unterton. Formal aber ließe es sich auch als »ergo« lesen, nach all dem, was Zarathustra erlebt hat, nach seinen zehn Jahren sprachloser Höhleneinsamkeit beginnt er jetzt also zu sprechen, kann also sprechen oder spricht also doch. Die Titelei hält das Paradox von Schrift und Rede in der Schwebe und verweigert einsinnige Auflösungen.

Der Titel »Also sprach Zarathustra« fungiert indes auch als Incipit-Formel, die den unmittelbaren Einsatz des Erzählers der Vorrede einleitet, wie es sonst Formeln in frühneuzeitlichen und mittelalterlichen anonymen Texten wie z.B. »Hier beginnt die Geschichte von ...« tun. Die dieser Tradition entsprechende Explicit-Formel findet sich inmitten der »Vorrede«: »Und hier endete die erste Rede Zarathustra's, welche man auch >die Vorrede $<$ heisst. « (Za, KSA 4, 20). Ein weiteres, durch Gedankenstriche noch gestisch unterstütztes Incipit-Explicit-Paar ist z.B. auch: »- Also begann Zarathustra's Untergang « (Za, KSA 4, 12 und 28!) und: »Also - endet Zarathustra's Untergang _ _ « « (Za, KSA 4, 220). Der Tempuswechsel vom Präteritum ins historische Präsens bewirkt eine szenische Vergegenwärtigung, welche Dramatik und Bedeutung des Geschehens zusätzlich betont.

Incipit und Explicit wurden indes traditionellerweise nicht vom Autor sondern z.B. vom Besitzer einer Handschrift als willkürliche Titel hinzugefügt und waren somit keine authentischen Bestandteile des Textes. ${ }^{43}$ Auch in Also sprach Zarathustra stehen diese Formeln zumeist, aber nicht immer, in keinem direkten Zusammenhang mit dem Textgeschehen und werden als eigene Absätze freigestellt.

Die Formel »Also sprach Zarathustra« taucht jedenfalls am Ende vieler Reden auf, und mit ihr wird anscheinend von einem anonymen Erzähler das Kapitel jeweils besiegelt. Zwar könnte dieser Erzähler manchmal Zarathustra selbst sein, der häufig über sich in der dritten Person spricht, doch das ist in diesen Fällen unplausibel. Die Explicit-Formeln verhalten sich zum Titel und den ihn kommentierenden Untertitel indes ebenfalls uneindeutig, zumal einige Kapitel andere oder keine Schlussformeln haben, oder in manchen Kapiteln die Erzählung nach der Formel trotzdem weitergeht (z.B. ZA III, Von der Seeligkeit wider Willen). Hinzu kommt, dass zu Beginn der späteren Bücher Stellen aus früheren als Motti sogar unter Angabe der Quelle zitiert werden, z.B. und nicht zufällig aus: »Z a r a t h u s t r a, vom Lesen und Schreiben. (I. p. 45.)« (Za, KSA 4, 192).

\footnotetext{
42 Grätz (Anm. 13), 371.

43 Vgl. Wolfgang Milde, »Incipit und Initia«, in: Lexikon des gesamten Buchwesens. 2. Auflage, Stuttgart 1991, 576 und $610 \mathrm{f}$.
} 
Die Frage nach dem Verhältnis von Schriftlichkeit und Mündlichkeit begleitet seit Platons Dialogen die Philosophiegeschichte, sie wird auch von Nietzsche immer wieder verhandelt ${ }^{44}$ und im Zarathustra durch das Textgeschehen permanent reflektiert. Im Kontrast zur breiten philosophischen Diskussion über das Problem des schriftlich fixierten Dialogs scheint es jedoch eine »Schriftvergessenheit der Erzähltheorie $\ll^{45}$ zu geben, obgleich auch das Erzählen wie der Dialog einen mündlichen Kommunikationszusammenhang suggeriert. Das Versäumnis hat zur Folge, dass ein für Also sprach Zarathustra fundamentales Problem des Erzählens übersehen wird: Wenn es nach dem Tode Gottes innerhalb der erzählten Welt des Zarathustra (außer für den >Weisen< in der Vorrede) keine wahren Sätze mehr gibt, dann kann es auch keine wahren Erzähler mehr geben! Man könnte zwar sagen, dass Gott oder der Mythos nicht die einzigen Instanzen sind, die die Wahrheit einer Erzählung verbürgen können, für Nietzsche jedoch bleibt ohne diese Garanten nur noch die Erinnerung an Zeiten, zu denen noch mit gutem Wissen erzählt und gelogen werden konnte. Nach dem Sturz der Metaphysik ist »die Unschuld der Lüge « dahin (NF 25 [101], KSA 11, 37). Der lügende Erzähler wird entweder zum verlogenen Erzähler oder aber er markiert, dass nunmehr nur noch relative, subjektive >Wahrheiten $<$ im Plural möglich sind. Nachdem »die >wahre Welt $<$ endlich zur Fabel wurde «, ist schließlich der alte Gegensatz von wahrer und scheinbarer Welt aufgelöst (Götzendämmerung, KSA 6, 80f.) und mithin der Sinn einer Differenzierung von faktualem und fiktionalem Erzählen verloren. Dass Zarathustra also gesprochen hätte, ist eine schon durch den Archaismus deutlich gemachte Fiktion; der Erzähler und seine Figuren sind erklärtermaßen erschrieben und erfunden, und sie erzählen wissentlich nur scheinbar Wahres oder wahr Scheinendes. Das Entscheidende an Nietzsches negativer Epopöe ist ihre sich als alternativlos wissende Parteinahme für die $>$ Lüge < der Darstellung und für den >lügenden< Erzähler. ${ }^{46}$ Man denke nur an die im poetologisch wegweisenden Kapitel »Von den Dichtern« angestellte Metareflexion, dass auch Zarathustra ein lügender Dichter sei oder an Nietzsches Sprachkritik in Ueber Wahrheit und Lüge im aussermoralischen Sinne. Es stellen sich also auch für die Erzähltheorie im Zarathustra die Fragen nach der Kunst als Lüge und der Lüge als Kunst in verschärfter Weise und dies nötigt zur Selbstreflexion der in Anschlag zu bringenden literaturwissenschaftlichen Kategorien. Weben auch wir zwangsläufig über dem Erzählfluss ein Begriffsnetz, das die Gegenstände überspinnt, statt sie zu erkennen? Fußt unser Neutralität und Objektivität heischendes Beschreibungssystem und die standardisierte Terminologie nicht ebenso auf szientifischen Prämissen, deren Gültigkeit der Text inhaltlich und formal durch seine Widersetzlichkeit infrage stellt? Inhaltlich durch die beständige Kritik an tradierten Denkkonventionen und petrifizierten Begriffssystemen, formal durch Textverfahren, die sich jedweder

\footnotetext{
44 Vgl. dazu Verf., »Der Dialog als philosophische Form bei Nietzsche«, Nietzsche-Studien 45 (2016), 81-112.

45 Uschi Kocher, »Wenn Erzähler lügen. Zum Problem des unwahrhaften Erzählers in Prosatexten der Frühen Neuzeit«, in: Corinna Laude, Ellen Schindler-Horst (Hrsg.), List, Lüge, Täuschung, Bielefeld 2005 (= Mitteilungen des Deutschen Germanistenverbandes 52, H. 3), 318-333.

46 Also genau gegenteilig dazu, wie Theodor W. Adorno den Formbruch im Roman der Moderne wertet. Vgl. ders., »Der Standort des Erzählers« (Anm. 24), 45.
} 
Kategorisierung entziehen? Eine jede literaturwissenschaftliche Beschreibung, auch die folgende, steht unter solchen Vorbehalten.

\section{IV.}

\section{Schrift versus Rede}

Im Unterschied zur Rede hat ein Buch ein Schriftbild. Betrachten wir zunächst das von Also sprach Zarathustra, sehen wir, dass die mündliche Rede meist durch Anführungszeichen typografisch markiert wird, manchmal aber auch nicht, etwa wenn in der Vorrede der Heilige spricht, während die Redepartien seines Dialogpartners Zarathustra in Anführungszeichen stehen. Auch gibt es den seltsamen Fall, dass gegen alle (deutschen) Lehrbuch-Vorschriften die Inquitformel einfach in die wörtliche Rede eingefügt wird: »»Nicht doch, sprach Zarathustra; du hast aus der Gefahr deinen Beruf gemacht, daran ist Nichts zu verachten. Nun gehst du an deinem Beruf zu Grunde: dafür will ich dich mit meinen Händen begraben.«« (Za, KSA 4, 22)

Falls sich diese Inkonsistenzen nicht schlicht Setzfehlern oder unbewußten Übernahmen französischer Konventionen verdanken, verdienten sie eine eigene Untersuchung, denn es könnte sich in dieser Verletzung grammatischer Regeln wieder eine grundsätzlichere Sprachskepsis manifestieren. Halten wir fest, dass solche Uneinheitlichkeiten nur im Schriftbild auffallen.

Jüngst hat Thomas Forrer anhand des Unterschieds zwischen dem >Aphorismus< Nr. 342 aus Nietzsches Die fröhliche Wissenschaft und des gleichen Passus aus der Vorrede zum Zarathustra bemerkt, dass der sogenannte >Aphorismus< absatzlos gesetzt sei, in Also sprach Zarathustra hingegen Nietzsche einen »Zeilenstil « ${ }^{47}$ gewählt habe: Nach jedem Satz folge ein Absatz, jeder Satz bilde eine »textuelle Einheit«, und, wie Forrer meint, auch eine metrische Einheit; durch den Drucksatz erscheine der Zarathustra daher als Versdichtung. ${ }^{48}$ Nietzsche lässt jedoch nicht nur in FW 342, sondern in allen sogenannten Aphorismen-Büchern selbst längere Texte immer absatzlos setzen, was den Kontrast zum Schriftbild des Zarathustra noch verstärkt. Gleichwohl unterschied Nietzsche in Ecce Homo zwischen den eingestreuten Liedern (KSA 6, 349), also den dithyrambischen Versen und den Reden Zarathustras (KSA 6, 343), weshalb man Letztere nicht allein aufgrund des Zeilenstils einfach als Verse deklarieren kann. Darüber hinaus kann man bei näherem Zusehen bemerken, dass nur die Reden und die Lieder Zarathustras in Zeilenstil gesetzt sind, die erzählenden Passagen jedoch absatzlos bleiben! Nur im Kapitel »Von der Erlösung « ist auch das längere Gespräch mit dem Bucklichten in größere Absätze unterteilt und so als Nacherzählung qualifiziert, denn wenn sich Zarathustra im Anschluss direkt an seine Jünger wendet, dann wird diese Rede wieder im Zeilenstil dargeboten. Das Druckbild des Zarathustra macht gerade auf die Differenz von Erzähl- und Redepartien aufmerksam.

\footnotetext{
47 Thomas Forrer, Nachwort zu: Friedrich Nietzsche, Sämtliche Gedichte, Stuttgart, 2019, 453-484, hier: 476.

48 Forrer (Anm. 47), ebd.
} 
Wer den Zarathustra als Erzählung auffassen will, muss diesen Wechsel zum Zeilenstil erklären können. Man könnte argumentieren, dass er deswegen kein Roman sondern eine erzählende Versdichtung ist, die eine Art polyphones homerisches Erzählen wiederbelebt, ${ }^{49}$ aber ohne den Anspruch, weiterhin unmittelbar vom Mythos künden zu können. Es deklariert sich das ganze Buch vielmehr schon durch die Figurennamen und den archaisierenden Titel als Legende und entsprechend übernimmt der Haupterzähler des Zarathustra für die historische Wahrheit seiner >Geschichten<, die er unzuverlässigen Historienbüchern entnommen hat, keine Gewähr. Aber auch die Legendenform ist eine Täuschung, deren scheinbare Schlichtheit von der Komplexität der Erzählkonstruktion nicht wirklich ablenken kann. ${ }^{50}>$ Legende $<$ wäre hier eher im wörtlichen Sinne von »wie zu lesen sei« aufzufassen, als Leseanweisung.

Dies zeitigt auch Konsequenzen für die Behauptung, Zarathustra agiere als Prophet, denn als solcher müsste er entweder selbst seine Eingebungen niederschreiben oder ein anderer seine Worte festhalten, denn erst dann vermag das Prophetenwort geschichtswirkende Kraft zu entfalten und in der Folge als Buch niedergeschrieben und Gesetz zu werden. Die Niederschrift erhält die Wirksamkeit des Wortes und verhindert, dass der Prophet dieses zurücknehmen kann. ${ }^{51}$ Wird indes ein Erzähler dazwischen geschaltet, ist alles wieder im Fluss, unsicher und offen und das Prophetentum seiner Gewähr beraubt. Auch das zweite Strukturelement prophetischer Rede, die vorausgehende Zwiesprache des Propheten mit Gott, die die Wahrheit der durch direkte Anrede, Visionen oder Träume geschickten Botschaften besiegelt, wird in Nietzsches Hauptwerk ersetzt durch die Zwiesprache Zarathustras mit sich selbst oder durch seine Traumvisionen. Diese begründen keinen eindeutigen Auftrag, ein Wort an einem bestimmten Ort genauso zu verkünden, wie bei den Propheten, die das Wort von Gott empfangen haben. Zarathustra ist kein Wahrheitsträger, seine Träume offenbaren nichts, seine Visionen sind Rätsel.

\footnotetext{
49 Vgl. den Anfang der Odyssee: »Sage mir, Muse, die Taten des vielgewanderten Mannes,

Welcher so weit geirrt, nach der heiligen Troja Zerstörung,

Vieler Menschen Städte gesehn, und Sitte gelernt hat,

Und auf dem Meere so viel' unnennbare Leiden erduldet,

Seine Seele zu retten, und seiner Freunde Zurückkunft.

Aber die Freunde rettet' er nicht, wie eifrig er strebte« (Übers. J. H. Voß).

$50 »$ Laß Dich durch die legendenhafte Art dieses Büchleins nicht täuschen: hinter all den schlichten und seltsamen Worten steht mein tiefster Ernst und meine ganze Philosophie. Es ist ein Anfang, mich zu erkennen zu geben - nicht mehr! — Ich weiß ganz gut, daß Niemand lebt, der so Etwas machen könnte, wie dieser Zarathustra ist«. Friedrich Nietzsche, Sämtliche Briefe, Kritische Studienausgabe (KSB), hrsg. Giorgio Colli, Mazzino Montinari, München, New York 1986, Bd. 6, 386.

${ }^{51}$ Siehe dazu: Herbert Haag, »Die Buchwerdung des Wortes Gottes in der Heiligen Schrift«, in: Die Grundlagen heilsgeschichtlicher Dogmatik, hrsg. Johannes Feiner, Magnus Löhrer, Bd. 1, Einsiedeln 1965, 289.
} 


\section{V.}

\section{Im Erzähllabyrinth}

Verschaffen wir uns also endlich einen Überblick, in dem wir die Erzählpartien sichten und die Einzelbeobachtungen zusammentragen. Da diese meist übersehen werden, wird hier Pedanterie zur Pflicht: Im Zarathustra wird der epische Rahmen durch den Bericht des Haupterzählers, nennen wir ihn Narrator 1, konstituiert, der meist sehr knapp die Stationen und Wanderungen Zarathustras schildert. Dieser Erzählerbericht auf Ebene 1 steht in der Regel im Präteritum, während Erzählerkommentare im Präsens erfolgen können. Wenn eine Figur etwas erzählt, wir also eine Erzählung in der Erzählung auf Ebene 2 vor uns haben, wird die Redesituation im Präsens geschildert und die jeweilige Geschichte ebenfalls im Präteritum erzählt. Dem ersten Eindruck zufolge leiten die Erzählpassagen die Reden ein; wir erkennen solche kurze Einleitungen sofort in der Vorrede und zu Beginn der vier Bücher des Zarathustra. Viele Reden oder Dialoge setzen aber unmittelbar (ohne Anführungszeichen) ein und erst am Kapitelende meldet sich dann der Erzähler mit der Formel »Also sprach Zarathustra« zu Wort. Doch es könnte auch sein, dass Zarathustra mit dieser Formel über sich in der dritten Person spricht, zumal immer wieder Wechsel von dritter zu erster Person im Text vollzogen werden. Dies geschieht z.B. in der Rede »Von den Hinterweltlern «, die mit einem Perspektivwechsel beginnt: »Einst warf auch Zarathustra seinen Wahn jenseits der Menschen, gleich allen Hinterweltlern. Eines leidenden Gottes Werk schien mir da die Welt« (Za, KSA 4, 35).

Mitunter werden die Bezüge auch verwischt, etwa wenn Zarathustra von sich in der dritten Person erzählt, z.B. zu Beginn von »Von tausend und Einem Ziele«: »Viele Länder sah Zarathustra und viele Völker: so entdeckte er vieler Völker Gutes und Böses. Keine größere Macht fand Zarathustra auf Erden, als gut und böse. Leben könnte kein Volk, das nicht schätzte; « (Za, KSA 4, 74). So weit klingt es noch wie ein Erzählerbericht, durch den Konjunktiv scheint sogar ein indirekter Gedankenbericht vorzuliegen, doch kurz darauf klärt der erläuternde Einschub »[...] also fand ich's« (ebd.) die Redesituation.

Umfang und Position der Erzähleinheiten variieren: Die Reden können kurze oder lange Einleitungspassagen, Schlusserzählungen und Binnenerzählungen aufweisen, aber es gibt auch das ganze Kapitel dominierende Erzählungen. Die Erzählrede übernimmt also durchaus nicht nur redeeinleitende, sondern auch redegliedernde und kommentierende Funktionen, zudem treibt sie zuweilen, vor allem im 4. Teil, die Handlung voran und dient der Kommunikation mit dem Leser.

Nur der erste Teil des Zarathustra ist mit der zusätzlichen Überschrift »Die Reden Zarathustras « versehen. Drei dieser 22 Reden aus dem ersten Teil erhalten dennoch längere Einleitungen des Erzählers. Im zweiten und dritten Teil häufen sich die erzählerischen Partien, im vierten Teil präsentiert sich nur noch das Kapitel »Vom höheren Menschen« als Rede, sonst dominiert die Erzählung.

Kurze Erzählereinleitungen finden sich auch im ersten Teil, obwohl in diesem noch die meisten Reden ohne jede erzählerische Exposition dargeboten werden, wie etwa: »Man rühmte Zarathustra einen Weisen« (Za, »Von den Lehrstühlen der Tugend $\ll$ KSA 4, 32). Doch selten eröffnen diese kurzen Einleitungen einen einfachen 
unproblematischen Einstieg in die Rede, meist enthalten sie bereits eine Falle. Hier ist z.B. unklar, auf welches »man« sich der Erzähler beruft. Tückisch sind auch die folgenden Eröffnungen:

Zarathustra's Auge hatte gesehn, dass ein Jüngling ihm auswich. Und als er eines Abends allein durch die Berge gieng, welche die Stadt umschliessen, die genannt wird >Die bunte Kuh $<$ : siehe, da fand er im Gehen diesen Jüngling, wie er an einem Baume gelehnt sass und müden Blickes in das Thal schaute. Zarathustra fasste den Baum an, bei welchem der Jüngling sass, und sprach: (Za, Vom Baum am Berge, KSA 4, 51).

Zunächst wird an ein vor unbestimmter Zeit vergangenes Geschehen im Plusquamperfekt erinnert, dann wechselt das Erzähltempus ins Präteritum und plötzlich wird der Leser auf irritierende Weise mit der biblischen Formel »siehe, da« angesprochen.

In »Von der schenkenden Tugend 2 « teilt der Erzähler neutral mit, dass sich die Stimme Zarathustras verändert habe: »Hier schwieg Zarathustra eine Weile und sah mit Liebe auf seine Jünger. Dann fuhr er fort also zu reden: - und seine Stimme hatte sich verwandelt« (Za, KSA 4, 99). Im folgenden Teilkapitel (»Von der schenkenden Tugend $3 \ll$ ) gibt er die Neutralität auf und stellt einen spekulativen Vergleich an: »Als Zarathustra diese Worte gesagt hatte, schwieg er, wie Einer, der nicht sein letztes Wort gesagt hat; lange wog er den Stab zweifelnd in seiner Hand. Endlich sprach er also:« (Za, KSA 4, 101, Hervorh. CZ).

Im zweiten Teil findet sich eine kurze Einleitung noch in »Von den Priestern« (Za, KSA 4, 117), im vierten Buch in »Das Lied der Schwermuth « und »Das Eselsfest 1,2,3.«. Zuweilen kann sich der Erzähler auch sofort nach dem unmittelbaren Redeeinsatz zu Wort melden, die Rede mit Gedankenstrichen unterbrechend: »»Seit ich den Leib besser kenne, « - sagte Zarathustra zu einem seiner Jünger - »ist mir der Geist nur noch gleichsam Geist««. Die weitere Rede ist dann mit Inquitformeln durchzogen, bis sich in der Mitte der Rede der Erzähler nochmals zu Wort meldet und sich des Irrealis zu bedienen beginnt: »Als Zarathustra so sprach, zürnte ihm sein Jünger, aber er schwieg. Und auch Zarathustra schwieg; und sein Auge hatte sich nach innen gekehrt, gleich als ob es in weite Fernen sähe. Endlich seufzte er und holte Athem.«(Za, KSA 4, 161, Hervorh. CZ) Es kommt aber auch vor, dass sich der Erzähler nur innerhalb einer Rede meldet, so im dritten Teil in »Der Wahrsager« oder in Teil IV von »Unter den Töchtern der Wüste 1«: »Also sprach der Wanderer und Schatten« ... » KSA 4, 379).

Kurze Schlusserzählungen beenden die Kapitel auch manchmal noch nach der Schlussformel, so zuerst in Teil I in »Von den drei Verwandlungen«: »Also sprach Zarathustra. Und damals weilte er in der Stadt, welche genannt wird: die bunte Kuh« (Za, KSA 4, 31, vgl. a.: »Von den Abtrünnigen«, »Unter Töchtern der Wüste 1«).

Mit kurzer Einleitung und kurzer Schlusserzählung werden hingegen im III. Buch die Reden gerahmt: »Vom Vorübergehen« (Za, KSA 4, 225), auch noch mit einer Unterbrechung durch den Erzähler in der Mitte, und »Von der Seligkeit wider Willen $\ll$. 
Längere Einleitungen haben die Kapitel »Vom Biss der Natter«, »Von der schenkenden Tugend $1 \ll$ im ersten Teil, »Vom Kind mit dem Spiegel« im zweiten Teil, und »Vom Vorübergehen « im dritten Teil, im 4. Buch »Das trunkne Lied I / II.«

Hervorzuheben sind jene Kapitel, die von der Erzählerrede nicht nur eingeleitet, sondern weitgehend durcherzählt und zugleich gegliedert werden. Die Erzählerrede dominiert die »Vorrede « sowie im zweiten Teil die Kapitel »Das Tanzlied « und »Von grossen Ereignissen«. Im letztgenannten findet sich noch eine durch den die Gattung anzeigenden Erzählerkommentar eingeleitete Binnenerzählung: »Und dies ist die Erzählung von Zarathustras Gespräch mit dem Feuerhunde« (Za, KSA 4, 168. Hervorh. CZ). Im dritten Teil bestimmt die Erzählrede viele Kapitel. Erkennbar nehmen in diesem Buch die Anteile des Haupterzählers im Verlauf immer stärker zu, bis die epischen Partien die Kapitel schließlich durchgängig gliedern. ${ }^{52}$

Davon klar zu unterscheiden sind jedoch die Erzählungen Zarathustras. Denn Zarathustra redet ja nicht nur, sondern er erzählt häufig auch. Seine Erzählungen können vom Haupt-Erzähler direkt eingeleitet werden: »Als Zarathustra diess einmal seinen Jüngern erzählte, fragten sie: »Und was, oh Zarathustra, ist die Moral deiner Geschichte? « Zarathustra antwortete darauf also:« (Za, KSA 4, 88). Zuvor aber hatte der Erzähler die Geschichte vom Biss der Natter bereits erzählt. Mit der Mitteilung, dass auch Zarathustra selbst anderen über sein Erlebnis berichtet hat, wird die Ebene gewechselt. Der Clou ist hier, dass Zarathustra geschlafen hatte, als die Natter ihn biss. Entweder hätte er die Geschichte anders erzählen müssen oder muss sie selbst erzählt bekommen haben, denn er kann nicht über das gleiche Wissen wie der Erzähler und wir Leser verfügen. An anderer Stelle wird diese Diskrepanz thematisiert und bereinigt: »Als ich im Schlafe lag, da frass ein Schaf am Epheukranze meines Hauptes, - frass und sprach dazu: »Zarathustra ist kein Gelehrter mehr«. Sprach's und gieng stotzig davon und stolz. Ein Kind erzählte mir's.« (Za, »Von den Gelehrten«, KSA 4, 160)

\footnotetext{
52 Vgl. »Der Wanderer«: »Also sprach Zarathustra im Steigen zu sich, mit harten Sprüchlein sein Herz tröstend: denn er war wund am Herzen wie noch niemals zuvor. Und als er auf die Höhe des Bergrückens kam, siehe, da lag das andere Meer vor ihm ausgebreitet: und er stand still und schwieg lange. Die Nacht aber war kalt in dieser Höhe und klar und hellgestirnt. Ich erkenne mein Loos, sagte er endlich « (Za, KSA 4, 190f.); »Also sprach Zarathustra auf der Spitze des Berges, wo es kalt war; als er aber in die Nähe des Meeres kam und zuletzt allein unter den Klippen stand, da war er unterwegs müde geworden und sehnsüchtiger als noch zuvor « (Za, KSA 4, 191); »Also sprach Zarathustra und lachte dabei zum andern Male: da aber gedachte er seiner verlassenen Freunde — , und wie als ob er sich mit seinen Gedanken an ihnen vergangen habe, zürnte er sich ob seiner Gedanken. Und alsbald geschah es, dass der Lachende weinte: - vor Zorn und Sehnsucht weinte Zarathustra bitterlich.« (Za, KSA 4, 196). Vgl.: »Vom Gesicht und Räthsel« (als Traumerzählung), »Von der Seligkeit wider Willen«, »Von der verkleinernden Tugend $1 \ll, »$ Der Genesende«. Im 4. Buch sind es: »Das Honigopfer«, »Der Nothschrei«, »Gespräch mit den Königen«, »Der Blutegel «, »Der Zauberer«, »Ausser Dienst«, »Der hässlichste Mensch«, »Der freiwillige Bettler«, »Der Schatten«, »Mittags«, »Die Begrüssung«, »Das Abendmahl«, »Das Lied der Schwermuth«, »Von der Wissenschaft«, »Die Erweckung«, »Das Nachtwandlerlied 1 und $2 \ll, ~ »$ Das Zeichen«.
} 
VI.

\section{Das Erscheinen des Erzählers}

Es ist an der Zeit, die unterschiedlichen Weisen, wie die Erzähler in dieser Schrift sowohl auftauchen als auch im Verborgenen wirken, genauer in Augenschein zu nehmen. An manchen Stellen wird explizit gemacht wer erzählt, so am offensichtlichsten zu Beginn des Kapitels »Von alten und neuen Tafeln«, wenn der müßig wartende Zarathustra sich selbst mit dem Erzählen seiner eigenen Lebensgeschichte die Zeit vertreiben will. Er agiert hier also als autodiegetischer Erzähler:

Hier sitze ich und warte, alte zerbrochene Tafeln um mich und auch neue halbbeschriebene Tafeln. (...) Dess warte ich nun: denn erst müssen mir die Zeichen kommen, dass es m e i n e Stunde sei, — nämlich der lachende Löwe mit dem Taubenschwarme. Inzwischen rede ich als Einer, der Zeit hat, zu mir selber. Niemand erzählt mir Neues: so erzähle ich mir mich selber. — Als ich zu den Menschen kam, da fand ich sie... (Za, KSA 4, 252)

Der Tempuswechsel vom Präsens ins Präteritum markiert den Übergang von dem im szenischen Modus in autonomer Figurenrede seine eigene Erzählsituation kommentierenden Ich-Erzähler Zarathustra zur Erzählung als Gedankenzitat im narrativen Modus. ${ }^{53}$ Zarathustra hat, wie er uns mitteilt, die alten und neuen Erzählungen auf den Tafeln gelesen, nun beginnt er selbst zu erzählen, aber nicht mehr für uns. Die folgende Erzählung, der wir von nun an vermeintlich heimlich zuhören, aber gleichsam gemeinsam mit Zarathustra auf einer weiteren Tafel lesen, ist als Selbstgespräch deklariert. Es bietet, da es ja die eigene, bereits erzählte Lebensgeschichte wiederholt, weder den Lesern noch Zarathustra selbst Neues, sondern ordnet lediglich Bekanntes neu.

Nun aber wird es vertrackt: Das ganze Kapitel ist in 30 nummerierte Abschnitte unterteilt. Mit Beginn von Abschnitt 2 hebt die Erzählung Zarathustras an, der in extremer Zeitraffung einige Stationen seines bisherigen Wirkens Revue passieren lässt und dabei die einst gehaltenen Reden, die anhand von Schlüsselworten wiederzuerkennen sind, zu Kernbotschaften verdichtet. Damit aber offeriert Zarathustra zugleich eine teils alternative Lesart zur bisherigen Darstellung des anonymen Haupterzählers (Narrator 1), etwa wenn er die für den Erzählstatus ohnehin maßgebliche Rede »Von den Dichtern« aus Teil II wie folgt erinnert und kommentiert: »Daß ich nämlich in Gleichnissen rede, und gleich Dichtern hinke und stammle: und wahrlich, ich schäme mich, daß ich noch Dichter sein muß! -« (Za, KSA 4, 243) Von der Scham des Dichter-Seins war zuvor aber nie die Rede und auch nicht davon, dass das Dichten überwunden werden könnte. Das wäre eine deutliche Abschwächung des aus der Perspektive von Narrator 1 erzählten Bekenntnisses Zarathustras, auch er sei ein lügender Dichter, denn das Lügen ist in einer Welt des Scheins prinzipielle Bedingung allen Sprechens. Diese Metareflexion liegt erkennbar auf einer

\footnotetext{
53 Zur erzähltheoretischen Diskussion der Funktion des Tempuswechsels durch den Erzähler siehe grundlegend: Imelda Rohrbacher, Poetik der Zeit. Zum Historischen Präsens in Goethes »Die Wahlverwandtschaften«, Göttingen 2016.
} 
höheren Ebene und transzendiert das eingeschränkte Bewusstsein des Protagonisten, der in seiner eigenen Rückschau zu erkennen gibt, dass er das Grundproblem, dass er selbst nicht nur ein lügender, sondern zudem auch ein erdichteter Held ist, nicht durchschaut - er hat von seiner Lage nur ein Bewusstsein, »wie die auf Leinwand gemalten Krieger von der auf ihr dargestellten Schlacht« (GT, KSA 1, 47, vgl. a. MA I 160: »Geschaffene Menschen«). Andererseits verrät Zarathustra Dinge, die der Erzähler zu diesem Zeitpunkt noch verschwiegen hat, nämlich dass er das »Wort >Übermenschく vom Wege« (Za, KSA 4, 248) aufgelesen, also irgendwo gelesen hat. Die Binnenerzählung erstreckt sich jedoch nicht über das ganze Kapitel - schon inmitten von Abschnitt 3 wird sie mit einem Wechsel ins Präsens unterbrochen:

- Diess hiess ich ihnen Erlösung, Diess allein lehrte ich sie Erlösung heißen. -

Nun warte ich meiner Erlösung - , dass ich zum letzten Male zu ihnen gehe. Denn noch ein Mal will ich zu den Menschen: unter ihnen will ich untergehen, sterbend will ich Ihnen meine reichste Gabe geben! Der Sonne lernte ich das ab. (Za, KSA 4, 249).

Daraufhin ergreift wieder der Haupterzähler das Wort und schließt den Kreis: »Der Sonne gleich will auch Zarathustra untergehen: nun sitzt er hier und wartet, alte zerbrochene Tafeln um sich und auch neue Tafeln, halbbeschriebene.« (Za, KSA 4, 249)

Dieser letzte Passus könnte auch von Zarathustra selbst gesprochen sein, der dann nicht mehr wie zu Beginn in der Ich-Form, sondern von sich in der dritten Person redete - in diesem Falle erzeugte er selbst über die Metalepse ein zirkuläres Erzählen in moderner Manier und würde als Binnenerzähler die Erzählung des Haupterzählers von seinem eigenen Untergang kommentieren. Man kann es nicht eindeutig entscheiden. Doch klar scheint nun, dass Figurenrede und Erzählerstimme gerade nicht einfach zusammenfallen, denn inszeniert wird deren mehrsinniges Zusammenund Widerspiel.

Mit Abschnitt 4 beginnt Zarathustra aber wieder unmittelbar zu imaginierten Brüdern zu sprechen: »Siehe, hier ist eine neue Tafel« (ebd.) Nach dem Rückblick wird er nun bis zum Ende des Kapitels Sprüche für nеue Tafeln liefern, Sprüche also, die wieder auf Tafeln niedergeschrieben werden sollen. Die Binnenerzählung Zarathustras erstreckt sich somit lediglich über 2 der 30 Abschnitte. Solche Einschübe gibt es öfters dann, wenn Zarathustra innerhalb einer Rede anderen oder sich selbst von vergangenen Ereignissen erzählt - meist sind dies Nacherzählungen von seinen Träumen oder - wie in »Von den Hinterweltlern « - von Jugend-Illusionen. Ihr Status wird zuweilen explizit angezeigt, etwa mit eigener Schlussformel: »Also erzählte Zarathustra seinen Traum und schwieg dann « (Za, KSA 4, 174). ${ }^{54}$

Doch was ist mit diesem Erzähler auf Ebene 1, der Zarathustra jene Träume zuschreibt, die dieser dann erzählt? Es ist ein Erzähler, der selbst nicht in der von ihm erzählten Geschichte vorkommt, ein >extradiegetischer-heterodiegetischer Erzähler. Dieser Erzähler meldet sich nirgends mit »ich« zu Wort, er bleibt anonym, tritt

54 Vgl. dazu Claus Zittel, »>Nachtwandler des Tages $<$. Traumpoetik und Parodie in Nietzsches Also sprach Zarathustra«, in: Pelloni, Schiffermüller (Hrsg.) (Anm. 4), 125-169. 
aber immer wieder durch Leseranreden und Erzählerkommentare in Erscheinung. Gleich zu Beginn des Textes konstatiert er, dass Zarathustras Herz sich nach 10 Jahren »endlich« verwandelt habe (Za, KSA 4, 5), später kommentiert er offener: »Da aber geschah Das, was an jenem erstaunlichen langen Tage das Erstaunlichste war: « (Za, KSA 4, 395). Zuweilen gibt er Hintergrundinformationen wie »denn es war verheissen worden « (KSA 4, 14) oder er bewertet das Geschehen insgesamt mit allgemeinen Urteilen wie: »Also begann Zarathustras Untergang « (Za, KSA 4, 28). Wenn er später mitteilt: »hier endet Zarathustra's Untergang « (Za, »Der Genesende $2 \ll$, KSA 4, 277) strukturiert er zugleich mit dem Schließen eines internen Kreises den Text. Zudem bezeichnet er die jeweilige Vortragsweise der Protagonisten und arrangiert so die Stimmen in der Erzählkomposition mit Angaben zu den verba dicendi: nicht nur »sprach « Zarathustra, sondern auch seine Seele und der Wahrsager (Za, KSA 4, 353), manches »erzählte« Zarathustra (Za, KSA 4, 87), z.B.: »Also erzählte Zarathustra seinen Traum« (Za, KSA 4, 174). Daneben verwendet er die Formeln: »also sang Zarathustra« (Za, KSA 4, 221), »also sprach« und »also sang der Zauberer« (Za, KSA 4, 371 u. 375) etc.

Zum Vorschein kommt der Erzähler mitunter, wenn er von der äußeren Perspektive in eine interne Perspektive wechselt. Die Umkehrung des Blicks wird durch die direkte Leseranrede und des nun vom Präteritum ins Präsens vollzogenen Wechsels des Erzähltempus sowie wieder durch Signalwörter angezeigt: >siehe da<, >ersichtlich <, > fürwahr<, > wahrlich<, >erstaunlich<, >da<. Damit wird des Öfteren der Übergang vom Berichten zum Zeigen (vom »telling « zum »showing «) fingiert, ${ }^{55}$ durch welchen die Leser in die erzählte Welt hineingezogen werden.

Eines Abends gieng Zarathustra mit seinen Jüngern durch den Wald; und als er nach einem Brunnen suchte, siehe, da kam er auf eine grüne Wiese, die von Bäumen und Gebüsch still umstanden war: auf der tanzten Mädchen mit einander. (Za, KSA 4, 139)

Schon gab uns jener alte Zauberer von seinem Schlimmsten zum Besten, und siehe doch, der gute fromme Papst da hat Thränen in den Augen und hat sich ganz wieder auf's Meer der Schwermuth eingeschifft. (Za, KSA 4, 379)

Als Zarathustra diess zu seinem Herzen gesagt hatte, lud er den Leichnam auf seinen Rücken und machte sich auf den Weg. Und noch nicht war er hundert Schritte gegangen, da schlich ein Mensch an ihn heran und flüsterte ihm in's Ohr — und siehe! Der, welcher redete, war der Possenreisser vom Thurme. (Za, KSA 4, 23).

Dieser Erzähler hat Innensicht, er vermag über die inneren Zustände der Protagonisten zu berichten und zitiert deren Gedanken in Anführungsstrichen: »>Was geschieht mir? < dachte Zarathustra in seinem erstaunten Herzen«. (Za, KSA 4, 406) Manchmal teilt er uns auch indirekt mit, etwa dass Zarathustra meint, ein Déjà-vu ${ }^{56}$ zu haben: »Zarathustra aber versank in eine schwarze Erinnerung, denn ihm war,

\footnotetext{
55 Wayne Booth, The rhetoric of fiction, Chicago 1961.

56 Zur Bedeutung des Déjà-vu bei Nietzsche siehe Otokar Fischer, »Eine psychologische Grundlage des Wiederkunftsgedankens. Bemerkungen über den literarischen Wert der >fausse reconnaissance«", Zeitschrift für angewandte Psychologie und psychologische Sammelforschung (ZAP) 5, 1911, 487-515.
} 
als habe er schon einmal in diesem Thal gestanden«. (Za, KSA 4, 327) Gelegentlich schildert der Erzähler Gedanken in Form der zitierten Rede und transponierten Figurenrede. Häufiger aber versteckt er sich ganz hinter der autonom inszenierten Figurenrede der Protagonisten. Insofern der Erzähler jedoch vorgibt, allwissend zu sein, handelt es sich um ein erzähltechnisches Täuschungsmanöver, denn was wie das Wissen des >allwissenden Erzählers` (sogenannte Nullfokalisierung) wirkt, kann genausogut eine Wahnvorstellung Zarathustras sein (Figurenperspektive, interne Fokalisierung). Hier ein Beispiel ohne direkte Leseransprache, sondern als Gedankenbericht (telling) und erlebter Gedankenrede:

Am späten Nachmittage war es erst, dass Zarathustra, nach langem umsonstigen Suchen und Umherstreifen, wieder zu seiner Höhle heimkam. Als er aber derselben gegenüberstand, nicht zwanzig Schritt mehr von ihr ferne, da geschah das, was er jetzt am wenigsten erwartete: von Neuem hörte er den grossen $\mathrm{N}$ o t h s c h r e i . Und, erstaunlich! diess Mal kam derselbige aus seiner eignen Höhle. (Za, KSA 4, 346, Kursivierung: CZ)

Beide Varianten können auch gemeinsam auftreten:

- sprach er und verwunderte sich über die Maassen. Und, fürwahr!, alle diese höheren Menschen, [...] sie lagen Alle gleich Kindern und gläubigen alten Weibchen auf den Knien und beteten den Esel an. Und eben begann der hässlichste Mensch zu gurgeln und zu schnauben, wie als ob etwas Unaussprechliches aus ihm heraus wolle; als er es aber wirklich bis zu Worten gebracht hatte, siehe, da war es eine fromme seltsame Litanei zur Lobpreisung des angebeteten und angeräucherten Esels. Diese Litanei aber klang also ... (Za, KSA 4, 384, Hervorh. CZ)

da aber geschah es, dass er sich plötzlich wie von unzähligen Vögeln umschwärmt und umflattert hörte, — das Geschwirr so vieler Flügel aber und das Gedräng um sein Haupt war so gross, dass er die Augen schloss. Und wahrlich, einer Wolke gleich fiel es über ihn her, einer Wolke von Pfeilen gleich, welche sich über einen neuen Feind ausschüttet. Aber siehe, hier war es eine Wolke der Liebe (Za, KSA 4, 402, Hervorh. CZ)

Es kommt auch vor, dass der Erzähler dramaturgische Mittel der Figurenrede aufgreift, um selbst in Form des Beiseitesprechens sich an einen imaginierten Adressaten oder sich selbst zu wenden. Dieses Stilmittel wird im Zarathustra z.B. von einer Figur verwendet und dann aber vom Erzähler in Klammern gesetzt und als solches markiert. So steht, als Zarathustra seinen Gästen ankündigt, er werde mit ihnen »deutsch und deutlich« reden, danach in Klammern:

(»Deutsch und deutlich? Dass Gott erbarm! sagte hier der König zur Linken, bei Seite; man merkt, er kennt die lieben Deutschen nicht, dieser Weise aus dem Morgenlande! Aber er meint »deutsch und derb« — wohlan! Das ist heutzutage noch nicht der schlimmste Geschmack! «) (Za, KSA 4, 350).

Wird hier das Beiseite-Sprechen einer Figur kommentiert, so übernimmt an anderen Stellen auch der Erzähler dieses Mittel, um, wie in Brechts epischem Theater, einen Verfremdungseffekt zu erzeugen: 
(Also sprach der Wahrsager; wie die Thiere Zarathustra's aber diese Worte hörten, liefen sie vor Schrecken davon. Denn sie sahen, dass was sie auch am Tage heimgebracht hatten, nicht genug sein werde, den Einen Wahrsager zu stopfen) (Za, KSA 4, 353).

(Hier aber geschah es, dass auch der Esel zu Worte kam: er sagte aber deutlich und mit bösem Willen I-A.) (Za, KSA 4, 306).

Unter drei Augen gesprochen, sagte erheitert der alte Papst (denn er war auf Einem Auge blind), (Za, KSA 4, 323)

(Und hier dehnte sich Zarathustra und fühlte, dass er schlafe.) ... (Aber da schlief er schon von Neuem ein, und seine Seele sprach gegen ihn und wehrte sich und legte sich wieder hin) — [...] (und hier erschrak er, denn ein Sonnenstrahl fiel vom Himmel herunter auf sein Gesicht) (Za, KSA 4, 344).

(Und Zarathustra zeigte mit den Händen nach oben) (Za, KSA 4, 393).

Hier markieren die Regieanweisungen in Klammern eine Distanz, der Erzähler klammert seinen Kommentar ein und sich zugleich aus dem Geschehen aus. Aber es gibt auch selbstreflexive Gedankenzitate auf der Ebene der erzählten Wirklichkeit, etwa wenn »Der Wanderer« sich in seinem Gesang unterbricht und diesen kommentiert:

- umsphinxt, dass ich in Ein Wort

Viel Gefühle stopfe:

(Vergebe mir Gott

Diese Sprach-Sünde!) (Za, KSA 4, 378)

$\mathrm{Ob}$ es sich um Figurenrede, erlebte Rede oder Erzählerkommentar handelt, ist hingegen bei jener, auch von Pettey ${ }^{57}$ als bedeutsam angeführten Stelle unentscheidbar: »Als Zarathustra dies gesagt hatte, antwortete der Sterbende nicht mehr; aber er bewegte die Hand, wie als ob er die Hand Zarathustras zum Danke suche.« (Za, Vorrede, KSA 4, 22, Hervorh. CZ).

Überdies gibt der Erzähler selbst immer wieder zu, dass auch er nur auf unsicherer Quellenbasis berichtet »wie geschrieben steht« (KSA 4, 308, 333). Seiner Erzählung möge glauben, wer noch an die Wahrheit heiliger Bücher glaubt, also nur die Dummköpfe. Das bedeutet aber, dass die aus der Figurenperspektive mitgeteilten, teils ekstatischen Visionen Zarathustras durch den Erzähler gerade nicht objektiv bestätigt werden:

»- Als aber Zarathustra diese Worte gehört hatte, — was glaubt ihr wohl, dass sich da mit seiner Seele zutrug? « (ZA, KSA 4, 328). »Aber, Wunder über Wunder! was musste er da mit seinen eignen Augen sehn!«(KSA 4, S. 388). »Und was glaubt ihr wohl, dass damals sich zutrug? «(ZA, KSA 4, 396). »Diess mag sich so verhalten haben oder auch anders und wenn in Wahrheit an jenem Abende der Esel nicht getanzt hat, so geschahen doch damals grössere und seltsamere Wunderdinge als es das Tanzen eines Esels wäre. Kurz, wie das Sprichwort Zarathustra's lautet: >was liegt daran!«« (ebd.). »und wer möchte

\footnotetext{
57 Pettey (Anm. 12), 89.
} 
auch errathen, welche Gedanken Zarathustra dabei über die Seele liefen?« (Za, KSA 4, 397).

An solchen markanten Stellen, an denen sich der Erzähler unmittelbar zu erkennen gibt, erweist er sich entweder als kalkuliert unzuverlässig oder aber als für seine Erzählung ungeeignet. ${ }^{58}$ Diese Stellen rechnen mit einem idealen Leser, der den Erzähler kritisch zu beurteilen vermag und durchschaut, dass dessen Erzählintention nicht im Text realisiert wurde, ja mehr noch, dass sie nicht mehr realisiert werden kann, da nach dem Tode Gottes kein Erzählen mehr beanspruchen kann, eine wahre Geschichte wiederzugeben.

\section{VII.}

\section{Polyphones Finale}

Weil der Erzähler des Zarathustra und Zarathustra als Erzähler sowie alle sprechenden Figuren das gleiche Vokabular und die gleichen Redeformeln verwenden, hat dies eine Interpretin zur Behauptung verleitet: »Polyphon ist das Werk wohl kaum, denn alle Stimmen sind Echos der einen Stimme Zarathustras ${ }{ }^{59}$. Doch ein solcher Eindruck beruht auf einer höchst ungenauen Wahrnehmung und würde von einem feineren Gehör - »wer Ohren hat, zu hören, der höre« (GM I 5, KSA 5, 262) sogleich korrigiert - worüber uns der Erzähler selbst belehrt:

Und, erstaunlich! diess Mal kam derselbige aus seiner eignen Höhle. Es war aber ein langer vielfältiger seltsamer Schrei, und Zarathustra unterschied deutlich, dass er sich aus vielen Stimmen zusammensetze: mochte er schon, aus der Ferne gehört, gleich dem Schrei aus einem einzigen Munde klingen. (Za, KSA 4, 346)

Es ist der »Nothschrei«, der zwar als ein einziger vernommen wird, aber dennoch aus vielen Kehlen kommt. Bei einer solcherart verdeckten Polyphonie kommt es auf das Unterscheiden an, das die Perzeption in Apperzeption überführt. Dies gilt gerade auch dann, wenn man eine »Durchlässigkeit von Erzählerbericht und Figurenrede « aufgrund der gleichen Sprechweise beobachtet, denn die Funktionen des Erzählens sind sehr verschieden. ${ }^{60}$ Katharina Grätz hat überhaupt das Vorherrschen eines dramatisch-szenischen Modus konstatiert, da im Zarathustra »nicht die Erzähler, - sondern die Figurenrede, die sich fast vollständig von der vermittelnden

\footnotetext{
58 Eine andere Leseerfahrung als ein absichtlich oder unabsichtlich unzuverlässiger Erzähler bewirkt ein für seine Erzählung ungeeigneter Erzähler - Dorrit Cohn nennt diesen einen »discordant narrator«: Vgl. Dorrit Cohn, »Discordant Narration«, Style 34, 2 (2000), 307-316.

59 Doreen Wohlleben, »Friedrich Nietzsches Zarathustra im poetologischen Spannungsfeld von Schatten und Erscheinung «, in: Mayer (Hrsg.) (Anm. 4), 125-138, hier: 135.

60 Grätz (Anm. 13), 370 f. Bereits Kunne-Ibsch (Anm. 13), 218 verwies hingegen zu Recht auf die »deutliche Trennungslinie zwischen dem discours du narrateur und dem discours des characteres i im Zarathustra.

61 Grätz (Anm. 13), 367.
} 
Erzählinstanz ablöst « ${ }^{61}$ dominiere. Entsprechend konzentriert sie sich bei ihrer Analyse auf die Zarathustra-Figur, obgleich sie um die Bedeutung des Erzählers weiß. ${ }^{62}$ Enrico Müller wiederum insistiert auf der »Nachrangigkeit der Redesequenzen «, da diese stets in die Erzählhandlung eingebunden seien. ${ }^{63}$ Pettey betont hingegen die Spannung zwischen narrativen und szenisch-mimetischen Passagen und spricht von einem Konflikt zwischen »diegesis and mimesis «. ${ }^{64}$ Dieser Konflikt würde jedoch eskamotiert, wenn man entweder die Figurenrede oder den Erzählerbericht zu sehr in der Analyse privilegierte. Beachtet man hingegen die Trennlinien, so zeigt sich, dass der Haupterzähler und die Figuren durchaus unterschiedliche Erzählmanöver durchführen und vor allem aber, dass es auf ihr Wechselspiel ankommt. Andernorts habe ich auf die Fiktionalisierungsstrategien und anschließenden Fiktionsbrüche hingewiesen, die ausschließlich auf das Konto des Haupterzählers gehen, während bei Zarathustra zunehmend die Zweifel an seiner eigenen Rollenidentität die Zu- und Einordnung seines Erzählens erschweren, bis auch er als konsistenter Erzähler nicht mehr eindeutig zu greifen ist. ${ }^{65}$ Wenn Zarathustra erzählt, schwingen stets die Fragen mit, welches $>$ Ich $<$ hier gerade und warum auf diese besondere Weise was erzählt. Zuweilen übernehmen aber auch andere Figuren die Hauptstimme, ohne dass diese mit jener Zarathustras zusammenstimmen muss. Die Polyphonie der vielen Stimmen im Zarathustra ergibt wie auch der gemeinsame Notschrei keine Harmonie.

Zarathustra erkundigt sich, wie bereits zitiert, bei den höheren Menschen selbst, ob er ihnen nun als Wahrsager, Träumender, Trunkener, Traumdeuter oder Mitternachtsglocke erscheine (Za, KSA 4, 402). Die Antwort wäre: als all das und noch vieles mehr. Entscheidend aber ist, dass es sich hierbei nicht um den einen Zarathustra handelt, der einfach in viele Rollen schlüpft und hinter Masken derselbe bleibt. Es gibt hier nichts als Rollen und die Sätze, die in einer Rolle gesprochen werden, können auch von anderen geäußert werden. Die vermeintliche Durchlässigkeit der Erzählstimmen ist vielmehr ein Auflösen der stabilen Beziehung vom Erzähler und seinen Sätzen. Entsprechend verwirrt nimmt Zarathustra daher zur Kenntnis: »Aber auch ich - bin ein Wahrsager« (Za, KSA 4, 303). Die Sprechweise und das Gesprochene sind nicht an eine dauerhafte Identität gekoppelt. Wenn Zarathustra in einem inneren Monolog überlegt: »Bin ich ein Wahrsager? Ein Träumender? Trunkener? Ein Traumdeuter? Eine Mitternachts-Glocke?/ Ein Tropfen Thau's? Ein Dunst und Duft der Ewigkeit?« (Za, KSA 4, 402) - so ist die Frage falsch gestellt, denn nicht er ist diese Rolle, sondern die jeweiligen Rollen konstituieren ihn erst als Figur, er existiert nur als Figur - genauer: als eine Vielheit von Figuren, die sogar einander widersprechen. Mit erzählerischen Mitteln wird die in der Rede »Von den Verächtern des Leibes « im Text formulierte Kritik an der Identität des Ich konsequent bis zu dessen Auflösung in viele, ihrer selbst nicht mächtige Pseudo->Ichs< umgesetzt.

Der Haupterzähler hingegen wird gar nicht erst als Figur greifbar. Das ist nicht weiter überraschend, sondern ein Normalfall des Erzählens; nicht normal ist, dass

\footnotetext{
62 Grätz (Anm. 13), 367.

63 Müller (Anm. 25), 71.

64 Pettey (Anm. 12), 101-106.

65 Vgl. Zittel, »Sprüche, Brüche, Widersprüche«.
} 
der Ort, von dem aus er redet, wechselt; er ist ein Wanderer, kein Olympier (als der er sich doch oft geriert). Seine Erzählweise führt den Leser nahezu unmerklich in Labyrinthe, aus denen er nicht mehr herausfinden soll. Doch ist der Haupterzähler kein Regisseur, der souverän die Erzählfäden seiner Geschichten in der Hand hält, vielmehr untergraben immer wieder Metalepsen und Inkonsistenzen seine Macht und Glaubwürdigkeit. Erwähnt habe ich bereits, dass es in der Rede »Von Grossen Ereignissen « eine Binnenerzählung gibt, die durch einen demonstrativen Hinweis des Erzählers eingeleitet wird: »Und dies ist die Erzählung von Zarathustras Gespräch mit dem Feuerhunde«. Dann aber, mitten in der Erzählung des Gesprächs, geschieht während der Schilderung Folgendes: »Endlich wurde er stiller, und sein Keuchen liess nach. Sobald $e r$ aber stille war, sagte $i c h$ lachend « und wenig später heisst es: »Also erzählte Zarathustra« (Za, KSA 4, 168, Hervorh. CZ). Unvermittelt wird unterwegs die Erzählperspektive gewechselt und das Erzählen von der Figur übernommen. Durch diese schleichende Transgression oder heimliche Metalepse werden die Grenzen der Erzählebenen verschoben und verwischt, man könnte auch sagen: die extradiegetische Ebene von der intradiegetischen »überblendet « und der Leser verwirrt. Wird so der extradiegetische Erzähler nun doch in die erzählte Welt hineingezogen und mit ihm auch wir Leser? Wird die Zulässigkeit von Grenzen überhaupt infrage gestellt? Wer ist der Autor einer Geschichte - seiner Geschichte? Es geschieht, wie Genette es beschreibt:

Das Verwirrendste an der Metalepse liegt sicherlich in dieser inakzeptablen und doch so schwer abweisbaren Hypothese, wonach das Extradiegetische vielleicht immer schon diegetisch ist und der Erzähler und seine narrativen Adressaten, d.h. Sie und ich, vielleicht auch noch zu irgendeiner Erzählung gehören. ${ }^{66}$

Die Erzählverfahren in Also sprach Zarathustra vermitteln nicht zuletzt die irritierende Einsicht, dass wir nicht mehr die Herrschaft über die Erzählung unseres eigenen Lebens haben. Wir erzählen nicht, wir werden erzählt. Mehr noch, wir leben in keiner geordneten Welt, sondern in einer, die wir nicht durchschauen. Es fehlen die Instanzen, die Sinn und Logik verbürgen könnten.

Ebenso wie scharfe Sentenzen in Also sprach Zarathustra die lyrischen Bilder sogleich wieder zersetzen, rhetorisch aufwendig evozierte Stimmungen durch Fiktionsbrüche im $\mathrm{Nu}$ verpuffen, entfalten sich auch die erzählerischen Fiktionen des Zarathustra-Textes nie konsistent. Sich andeutende Geschichten werden im Keim erstickt, ${ }^{67}$ Handlungsstränge durch Metalepsen gekappt oder ad absurdum geführt, Erzählfäden nicht ausgezogen, es gibt ein loses Nacheinander, aber keine kausal oder psychologisch plausibel motivierte Konsekution. Die traditionellen epischen Formmuster und das Schicksal der Figuren sind kontingent geworden. Die erzählerische Unordnung des Zarathustra-Textes reflektiert die Unordnung der Welt, sie nötigt zur Besinnung, dass der einfältige Traum eines kohärent erzählbaren Lebens in der Moderne ausgeträumt ist. Das Erzählen hat bei Nietzsche primär desintegrative Funktionen, es verweigert in der Kunst Ordnungen zu stiften, die die Illusion

\footnotetext{
66 Gerard Genette, Die Erzählung, 2. Aufl. München 1998, 169.

67 Elrud Kunne-Ibsch, »>Der Weg zum schönen Leben.< Enthistorisierung als Verfahren in der Erzählung des Jugendstils«, Neophilologus 57 (1973), 217-231 u. 317-329, hier: 324-326.
} 
aufrechterhalten, dass man sich im Chaos doch irgendwie geborgen fühlen kann. Gerade die Erzählverfahren konterkarieren die Heilsbotschaften von Nietzsches vermeintlichem Propheten, an die viele Interpreten blind sich weiterhin klammern. Wie später Musils Ulrich hat bereits Nietzsche erkannt, dass »dieses primitiv Epische abhanden gekommen [ist], woran das private Leben noch festhält, obgleich öffentlich alles schon unerzählerisch geworden ist und nicht einem >Faden $<$ mehr folgt, sondern sich in einer unendlich verwobenen Fläche ausbreitet. « ${ }^{68}$ Die erzählte Welt ist genauso unbehaglich wie die wirkliche Welt. Nietzsches Erzählkunst in Also sprach Zarathustra weist voraus auf die Roman-Ungetüme der Moderne.

Funding Open access funding provided by Università Ca' Foscari Venezia within the CRUI-CARE Agreement.

Open Access Dieser Artikel wird unter der Creative Commons Namensnennung 4.0 International Lizenz veröffentlicht, welche die Nutzung, Vervielfältigung, Bearbeitung, Verbreitung und Wiedergabe in jeglichem Medium und Format erlaubt, sofern Sie den/die ursprünglichen Autor(en) und die Quelle ordnungsgemäß nennen, einen Link zur Creative Commons Lizenz beifügen und angeben, ob Änderungen vorgenommen wurden.

Die in diesem Artikel enthaltenen Bilder und sonstiges Drittmaterial unterliegen ebenfalls der genannten Creative Commons Lizenz, sofern sich aus der Abbildungslegende nichts anderes ergibt. Sofern das betreffende Material nicht unter der genannten Creative Commons Lizenz steht und die betreffende Handlung nicht nach gesetzlichen Vorschriften erlaubt ist, ist für die oben aufgeführten Weiterverwendungen des Materials die Einwilligung des jeweiligen Rechteinhabers einzuholen.

Weitere Details zur Lizenz entnehmen Sie bitte der Lizenzinformation auf http://creativecommons.org/ licenses/by/4.0/deed.de.

68 Robert Musil, Der Mann ohne Eigenschaften, Hamburg 1952, 650. 